\title{
Immunohistochemical determination of p53 overexpression
}

\section{An easy and readily available method to identify progression in superficial bladder cancer?}

\begin{abstract}
Overexpression of $\mathrm{p} 53$, as determined by immunohistochemical staining with the murine monoclonal antibody DO7, was determined in specimens of 46 primary superficial transitional cell bladder tumours (14 TaG2, $10 \mathrm{~T} 1 \mathrm{G} 2,22 \mathrm{~T} 1 \mathrm{G} 3)$. A colon cancer specimen served as a positive control and normal mesenchymal cells in the specimens served as an internal negative control. An exceptionally high proportion $36 / 46(78 \%)$ of the specimens were found to stain positively for p53 in over $20 \%$ of the cell nuclei. After a median follow-up of 7 years, ten patients developed progressive disease. Of these ten patients nine demonstrated $\mathrm{p} 53$ positivity, resulting in a sensitivity of $90 \%$. However, 27 of the overall 36 patients (75\%) with p53-positive tumours did not progress to a higher stage or metastatic disease. These findings suggest that p53 overexpression is not of predictive prognostic value in superficial transitional cell carcinoma. With 7 of 14 specimens $(50 \%)$ of Ta tumours overexpressing p53, the results were suggestive of p53 mutation being an early event in carcinogenesis. When the threshold was set at $50 \%$ of the cell nuclei overexpressing p53,16/46 (35\%) classified as p53 positive. Of the 16 tumours staining positively for $\mathrm{p} 53$, $7(46 \%)$ progressed and $9(56 \%)$ did not. None of the Ta and $16(50 \%)$ of the T1 tumours classified as positive. This more stringent definition of positivity still does not identify p53 positivity as a single prognostic factor. With $50 \%$ of $\mathrm{T} 1$ tumours classifying as positive, we still find that p53 mutation may be an early event in carcinogenesis of bladder cancer.
\end{abstract}

Key words Bladder tumour - Carcinogenesis . p53 tumour-suppressor gene - Disease progression . Immunohistochemistry

F. C. Burkhard $(\otimes)$ - G. N. Thalmann - U. E. Studer Department of Urology, University of Berne, Inselspital, CH-3010 Berne, Switzerland

R. Markwalder

Department of Pathology, University of Berne, Inselspital, CH-3010 Berne, Switzerland

\section{Introduction}

Bladder cancer is a multistage progressive disease with an onset typically later in life. The disease encompasses a wide spectrum of malignant potential ranging from a mere inconvenience to fatal disease. About $70 \%$ of superficial transitional cell bladder cancers recur and 10-20\% progress to a higher stage, grade or metastatic disease. In comparison with superficial transitional cell carcinoma, the prognosis of muscle invasive tumours or metastatic disease is poor.

p53 is one of the most commonly found gene mutations in carcinogenesis and has been observed in $70 \%$ of colon cancers, $30-50 \%$ of breast cancers, $50 \%$ of lung cancers and $100 \%$ of small-cell lung cancers [12]. It has been shown to play an important diagnostic and prognostic role in a variety of tumours, but the molecular mechanisms by which it influences normal cell function and tumorigenesis remain unclear. p53 functions as a tumour suppressor gene, monitoring the integrity of the genome and inducing cell cycle arrest at the G1-S checkpoint if damage is found [11]. This allows time for repair mechanisms to act. p53 may play a role in inducing programmed cell death, if repair fails.

The 553 protein is coded for by a $16-$ to $20-\mathrm{kb}$ gene located on the short arm of chromosome 17. The product is a 393-amino-acid nuclear protein involved in the regulation of cell proliferation. The half-life of wild-type p53 is very short (6-20 $\mathrm{min})$. However, many missense mutations may induce mutations, which lead to a prolonged half-life of about $6 \mathrm{~h}$. Eighty per cent of mutations are missense mutations causing one amino acid to be substituted for another, usually altering protein conformation, and causing nuclear accumulation [9]. Not only mutations lead to a prolonged half-life of the $\mathrm{p} 53$ protein, but viral gene products (e.g. SV40 large T antigen, the adenovirus E1B protein and papillomavirus E6 protein) have been found to stabilize the wild-type p53 protein [14]. Furthermore, it seems that the stability of the p53 protein is influenced by other cellular oncogenic proteins such as MDM2 [15]. 
The protein encoded by the mutated p53 gene has a much longer half-life than wild-type p53 and allows for its detection by immunohistochemistry. Immunohistochemical staining is a widely available, easy and accurate method for evaluating mutations of $\mathrm{p} 53$.

Among the available antibodies, the monoclonal antibodies DO7 has been shown to have the highest specificity and sensitivity when combined with the target unmasking fluid (Kreatech, Amsterdam, The Netherlands) and then heated in a microwave oven for $5 \mathrm{~min}$ twice at $90^{\circ} \mathrm{C}$ $[1,2]$.

The optimal treatment for superficial bladder cancer is difficult to assess, as there is no easy and reliable method for identifying patients at risk of developing progressive disease. The aim of this study was to determine whether p53 overexpression as assessed by immunohistochemical staining can predict the development of a higher grade, stage or metastatic disease in patients with superficial bladder cancer and at what stage of carcinogenesis p53 overexpression occurs.

\section{Patients and methods}

Patients

Forty-six patients, 39 men and 7 women, with primary superficial transitional cell carcinoma of the bladder treated at the Department of Urology, University Hospital, Berne, between 1981 and 1993 were randomly selected. For these patients complete clinical, demographic and histopathological data were available and all cases were reviewed retrospectively. All patients were treated by transurethral resection and the formalin-fixed, paraffin-embedded specimens were examined. Median patient age at diagnosis was 63.7 years (range 4488 years). Median follow-up was 7 years (range 1-15 years) after initial diagnosis.

Of the 46 patients with superficial transitional bladder cell carcinoma, there were 14 patients with $\mathrm{TaG} 2$ and 32 patients with $\mathrm{T} 1$ disease ( 10 with $\mathrm{G} 2$ and 22 with $\mathrm{G} 3$ tumours) at initial diagnosis (Table 1).

\section{Immunohistochemistry}

Archival hematoxylin and eosin stained tissues were examined by a single pathologist (R.M.) in order to obtain representative sections from the superficial transitional bladder cancer specimens. Tumours were graded according to the WHO classification and staged according to the TNM system. Formalin-fixed, paraffin-embedded, archival tissue blocks from the 46 patients were sectioned and representative sections were chosen.

For immunohistochemical staining we used the murine monoclonal antibodies DO7 (Dako, Hamburg, Germany) and Pab1801 (Oncogene Science Inc., Manhasset, NY) to mutant and wild-type p53.

Table 1 Tumour stages and grades of 46 patients after transurethral resection for superficial transitional cell carcinoma

\begin{tabular}{llll}
\hline & G2 & G3 & Total \\
\hline Ta & 14 & 0 & 14 \\
T1 & 10 & 22 & 32 \\
Total & 24 & 22 & 46 \\
\hline
\end{tabular}

Staining procedures included deparaffinisation in ethanol followed by washing in TRIS-buffered saline, $\mathrm{pH}$ 7.4. Immunohistochemical examination was performed with the target unmasking fluid (TUF) antigen retrieval method (Kreatech, Amsterdam, The Netherlands) to enhance antigen retrieval. Microwave oven heating was performed as described by Beckstead [2] using a citrate buffer $\mathrm{pH}$ 6. Slides were then incubated with the primary DO7 monoclonal antibody at a dilution of 1:200 at room temperature for $60 \mathrm{~min}$ or with the primary monoclonal antibody Pab1801 at a dilution of 1:50 for $45 \mathrm{~min}$. The secondary antibody RAM/Ig was used for $45 \mathrm{~min}$ at a 1:30 dilution. After incubation with the avidin-biotin peroxidase complex, sections were stained with hematoxylin. A colon cancer specimen known to be p53 positive was stained as a positive control.

\section{Classification of immunohistochemistry}

Depending on the percentage of nuclei demonstrating a positive staining reaction with the monoclonal antibody DO7, tumours were classified into three groups: $<20 \%$ positivity, $20-50 \%$ positivity and $>50 \%$ positivity. Only staining of the cell nucleus was considered a positive reaction. The slides were evaluated independently by two investigators.

After evaluation of preliminary trials, the use of the antibody Pab1801 was discontinued as we noticed a higher degree of background staining in comparison with the antibody DO7.

\section{Results}

Taking a threshold of p53 nuclear overexpression in over $20 \%$ of cells, $36 / 46$ specimens ( $78 \%$ ) were considered positive and $10 / 46(22 \%)$ negative. The positive control (colon cancer specimen) stained positively in all tumour cell nuclei with a distinct demarcation at the tumour edge in each staining procedure. The normal mesenchymal cells in all specimens remained negative and served as an internal negative control. Figures 1 and 2 show staining of different tissue specimens.

The correlations between overexpression of $\mathrm{p} 53$, grade and stage were assessed (Table 2). A larger proportion of tumours with a higher grade or stage overexpressed p53. Fifty per cent of the Ta tumours and $91 \%$ of the T1 tumours overexpressed p53. Of the G2- 71\% and of the G3-classified tumours $86 \%$ demonstrated positivity. If the cutoff was placed at $>50 \%$ nuclear overexpression, none of the Ta tumours and $50 \%$ of the T1 tumours classified as positive (Table 2). After a median follow-up of 7 years, 10 of the 46 patients $(22 \%)$ progressed to a higher stage or developed metastatic disease. Of these ten progressive bladder tumours, nine $(90 \%)$ were positive for p53 in over $20 \%$ of the cells, whereas one (10\%) did not stain positively.

Overall 36 tumours classified as p53 positive of which $9(25 \%)$ developed into progressive disease and $27(75 \%)$ did not (Table 3). Applying a higher threshold of over $50 \%$ nuclear expression, 16/46 tumours were classified as positive. Seven tumours in the ten patients $(70 \%)$ with progressive disease classified as positive and three $(30 \%)$ as negative. Of the 16 p53-positive tumours, $9(56 \%)$ did not develop progressive disease (Table 3 ). Analysis of our results shows a sensitivity of $90 \%$ with a specificity of $25 \%$ for progression of bladder cancer when positivity is defined as $20 \%$ nuclear overexpression of $\mathrm{p} 53$. Setting the 


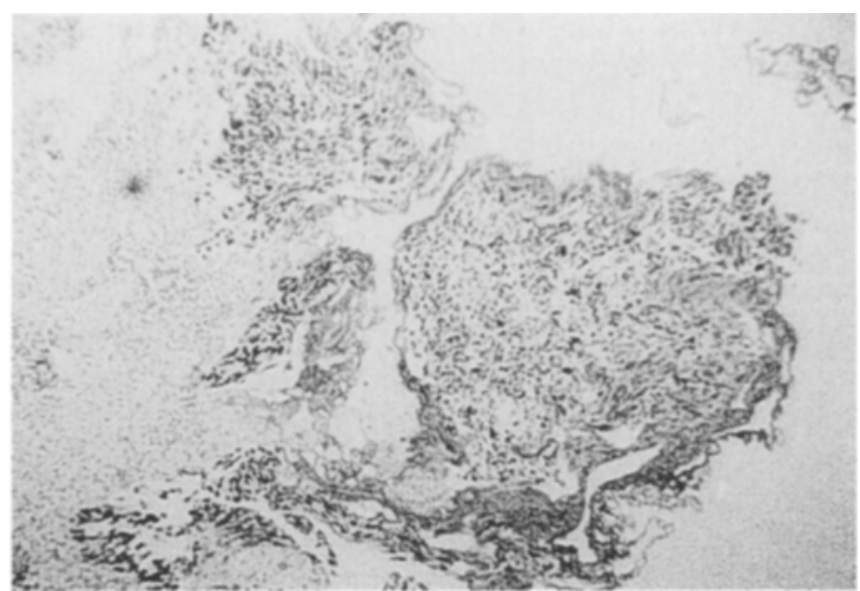

Fig. 1 Immunohistochemical determination of the antibody DO7 for overexpression of $\mathrm{p} 53$ in a colon cancer specimen, serving as a positive control

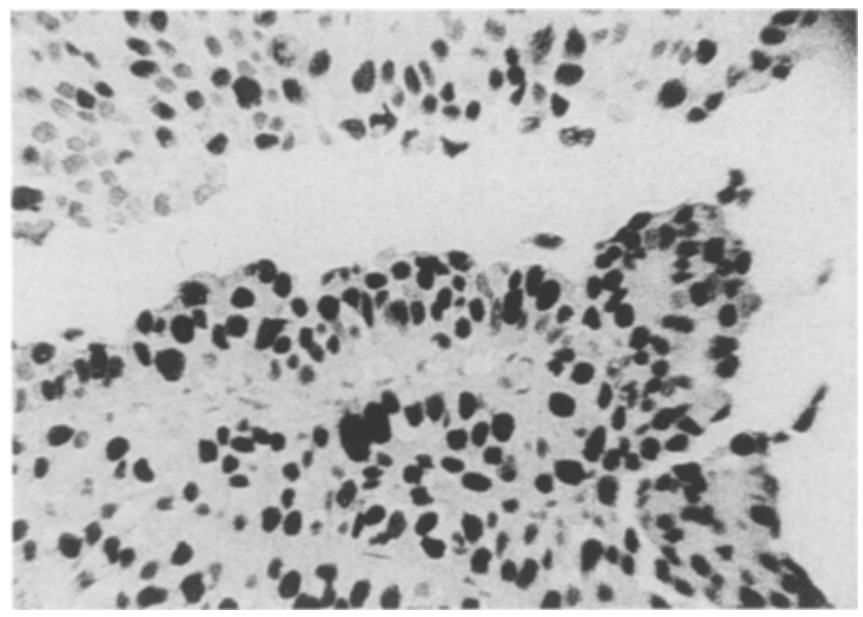

Fig. 2 Intense homogeneous overexpression of p53, as determined by immunohistochemistry with the antibody DO7, in a specimen with superficial transitional cell bladder carcinoma

Table 2 Relationship between overexpression of $\mathrm{p} 53$, grade and stage of bladder tumours

\begin{tabular}{llccc}
\hline & Total No. & p53<20\% & p53>20\% & p53>50\% \\
\hline Ta & 14 & $7(50 \%)$ & $7(50 \%)$ & $0(0 \%)$ \\
T1 & 32 & $3(9 \%)$ & $29(91 \%)$ & $16(50 \%)$ \\
Grade II & 24 & $7(29 \%)$ & $17(71 \%)$ & $4(17 \%)$ \\
Grade III & 22 & $3(14 \%)$ & $19(86 \%)$ & $12(54 \%)$ \\
Total & 46 & $10(22 \%)$ & $36(78 \%)$ & $16(35 \%)$ \\
\hline
\end{tabular}

Table 3 Tumour progression in regard to percentage of tumour cell nuclei demonstrating positive immunohistochemical staining

\begin{tabular}{llll}
\hline & Total & $\begin{array}{l}\text { Progression } \\
(\%)\end{array}$ & $\begin{array}{l}\text { No progression } \\
(\%)\end{array}$ \\
\hline$<20 \%$ & 10 & $1(10 \%)$ & $9(90 \%)$ \\
$>20 \%$ & 36 & $9(25 \%)$ & $27(75 \%)$ \\
$<50 \%$ & 30 & $3(10 \%)$ & $27(90 \%)$ \\
$>50 \%$ & 16 & $7(44 \%)$ & $9(56 \%)$ \\
\hline
\end{tabular}

cutoff point at $50 \%$ results in a decreased sensitivity of $70 \%$ and an improved specificity of $75 \%$.

\section{Discussion}

The following conclusions can be drawn from our results: (1) p53 overexpression as determined by immunohistochemical determination is frequent in superficial bladder cancer; (2) the results in our group of patients do not support the use of immunohistological p53 expression as a discriminating prognostic indicator in superficial cell carcinoma; and (3) p53 mutation may be an early event in carcinogenesis of bladder cancer.

Previous studies have shown changes in the $\mathrm{p} 53$ protein to occur in $11-64 \%$ of superficial transitional cell bladder tumours $[3,5,7,16,21-23]$. Interestingly, an exceptionally high proportion (78\%) of superficial bladder tumours in our group stained positively for p53 (Ta 50\%, T1 91\%). In our study we used the murine monoclonal antibody DO7, which recognizes mutant and wild-type p53 for staining procedures. Antigen retrieval was enhanced by target unmasking fluid and according to the microwave procedure. In a comparative study of six common antibodies, DO7 demonstrated the highest sensitivity and specificity for the p53 protein [1]. The most commonly used antibody, Pab1801, showed a lower sensitivity and specificity in the above-mentioned study. The use of the antibody DO7 could explain the high proportion of tumours with p53 overexpression in our study in comparison to others at the cutoff point of $20 \%$.

In T1 bladder tumours, Sarkis et al. [17] observed a correlation between $\mathrm{p} 53$ overexpression and disease progression. Gardiner et al. [7] could not relate p53 overexpression in T1 tumours to patient outcome and therefore did not support p53 immunohistochemical determination as a prognostic indicator in superficial bladder cancer [7]. Thomas et al. [23] demonstrated that significantly higher levels of p53 positivity (>10\% nuclear staining) were found in $\mathrm{T} 1$ bladder tumours with disease progression, but that tumour grade remained the most specific single predictor of progression [23]. In our group of patients we find a sensitivity of $90 \%$ combined with a specificity of $25 \%$ for tumour progression when both $\mathrm{T} 1$ and Ta tumours are included in the analysis. When analysing only the $\mathrm{T} 1$ tumours the sensitivity remains $90 \%$ and the specificity drops to $9 \%$.

A more stringent definition of positivity with a threshold at $50 \%$ results in positive staining of $50 \%$ of T1 tumours and none of the Ta tumours. This causes a slight decrease in sensitivity from $90 \%$ to $70 \%$ and improves specificity from $25 \%$ to $59 \%$. These results suggest that, whatever the threshold, overexpression of p53 as determined by immunohistochemistry may not be used as a discriminating predictive factor for progression in superficial bladder cancer.

However, by setting the threshold for positivity at $50 \%$, our results become more comparable with other published 
results (between $11 \%$ and $64 \%$ of p53-positive tumours). Interestingly, in these studies cutoff points ranged from $0 \%$ to $20 \%$ of cells with p53 nuclear overexpression [7, 16, 21-23]. One may speculate that in some instances overexpression of the wild-type p53 accounts for immunoreactivity, especially when particularly sensitive methods are applied. Possibly other mechanisms may influence the expression of the $\mathrm{p} 53$ protein such as viral gene products and cellular oncogenic proteins, which are known to stabilize wild-type p53 [11, 13, 15].

How the heterogeneity of p53 staining, found predominantly in specimens with a lower percentage of p53 overexpression, should be interpreted remains unanswered. It may be speculated that there are cells staining positively for p53, which are expressing p53 physiologically in response to damage or representing an early clone of cells with a p53 mutation in an otherwise negative neoplasm.

Another methodological problem in this context is the evaluation of immunohistochemical staining for $\mathrm{p} 53$, as there is no standardized form of evaluation and these methods are not quantitative. Furthermore, the intensity of staining, a rarely discussed matter, may influence the interpretation of results. Esrig et al. [4] reported that the intensity of staining varies due to the location of mutations. Not only do staining properties vary according to the location of missense mutations, but also different mutant alleles of the p53 gene may have different biological and chemical properties. It has been proposed that cancer patients with different p53 mutant alleles may have a different prognosis [13].

Esrig et al. [4] reported no evidence of p53 mutations by molecular analysis in $29 \%$ of bladder tumours with positive p53 immunoreactivity using the antibody Pab1801. This indicates that either immunohistochemical staining is more sensitive than single-strand conformational polymorphism analysis in detecting p53 mutations or that discordant cases represent tumours with accumulation of wildtype $\mathrm{p} 53$ protein without mutations at the $p 53$ locus.

Greenblatt et al. [8] reviewed 84 studies comparing immunohistochemical determination with sequencing in the same tumour sets and found positive immunohistochemical staining in $44 \%$ of tumours, while only $36 \%$ contained mutations recognized by single-strand conformational polymorphism analysis [8]. The sensitivity of immunohistochemical determination for $\mathrm{p} 53$ mutations in these studies was in the range of $36-100 \%$ and the positive predictive value was $63 \%$ (range $8-100 \%$ ). Thus, results must be interpreted with caution.

p53 nuclear overexpression has been suggested to be an early event, because it occurs in a high percentage of patients with carcinoma in situ $[18,20]$. Whether carcinoma in situ does progress to invasive bladder cancer remains unclear. Possibly the high percentage of $\mathrm{p} 53$ positivity in carcinoma in situ is more suggestive of a different molecular pathway leading to cancerogenesis. This agrees with the theory that carcinoma in situ tumour cells are so undifferentiated that they cannot grow invasively. p53 overexpression has been shown to correlate significantly with grade and stage, which suggests that $\mathrm{p} 53$ inactivation might be an early event in bladder cancer [24]. In the present study the association with grade and stage and the high percentage of p53 overexpression in Ta tumours further implicate that p53 inactivation may occur early in the evolution of bladder cancer. Possibly further genetic alterations are necessary to induce aggressive tumour growth.

It has been suggested that $\mathrm{p} 53$ staining might be predictive of chemosensitivity. Doxorubicin treatment can alter the p53 status of bladder tumours and p53 overexpression has been associated with doxorubicin resistance in the histocultures of seven superficial $\mathrm{Ta} / \mathrm{T} 1$ and nine invasive T2-T4 tumours [6]. Further research found p53 overexpression to be of independent prognostic value for survival in patients with invasive bladder cancer treated with neoadjuvant chemotherapy in a cohort of 90 patients [19].

Possibly p53 status will prove to be of prognostic value for therapy forms that influence the cell cycle. Further studies are needed to elucidate the potential value of p53 immunohistochemistry in predicting outcome and therapeutic response in selected patient groups.

\section{Conclusion}

Based on our results p53 overexpression is not a single predictive factor in the evaluation of superficial bladder cancer. In our study population, positive p53 staining was a frequent event, suggesting that p53 mutation may occur early in superficial transitional cell carcinogenesis. Although immunohistochemical determination is a simple and readily available procedure, the evaluation can prove difficult and the predictive value is limited. As p53 inactivation seems to be one step in a multistage carcinogenesis, further studies including other tumour suppressor genes and oncogenes are required. Since it seems unlikely that one genetic event is responsible for tumour progression in bladder cancer, this limited information obtained from $\mathrm{p} 53$ analysis is not surprising.

\section{References}

1. Baas IO, Mulder JWR, Offerhaus GJA, Vogelstein B, Hamilton SR (1994) An evaluation of six antibodies for immunohistochemistry of mutant $\mathrm{p} 53$ gene product in archival colorectal neoplasms. J Pathol 172:5

2. Beckstead JH (1994) Improved antigene retrieval in formalinfixed, paraffin-embedded tissues. Appl Immunohistochem $2: 274$

3. Dalbagni G, Presti JC Jr, Reuter VE, Zhang ZF, Sarkis AS, Fari WR, Cordon-Cardo C (1994) Molecular genetic alterations of chromosome 17 and p53 nuclear overexpression in human bladder cancer. Diagn Mol Pathol 2:4

4. Esrig C, Spruck III CH, Nichols PW, Chaiwun B, Stevens K, Groshen S, Chen S, Skinner DG, Jones PA, Cote RJ (1993) P53 nuclear protein accumulation correlates with mutations in the p53 gene, tumour grade, and stage in bladder cancer. Am J Pathol 143:1389

5. Esrig D, Elmajian D, Groshen S, Freeman JA, Stein JP, Chen S-C, Nichols PW, Skinner DG, Jones PA, Cote RJ (1994) Accumulation of nuclear p53 and progression in bladder cancer. N Engl J Med 19:1259 
6. Gan Y, Wientjes MG, Badalament RA, Au JL-S (1996) Pharmacodynamics of doxorubicin in human bladder tumours. Clin Cancer Res 2:1275

7. Gardiner RA, Walsh MD, Allen S, Rahman S, Samaratunge MLTH, Seymour GJ, Lavin MF (1994) Immunohistochemical expression of $\mathrm{p} 53$ in primary $\mathrm{pT} 1$ transitional cell bladder cancer in relation to tumour progression. $\mathrm{Br} \mathrm{J}$ Urol 73:526

8. Greenblatt MS, Benett WP, Hollstein M, Harris CC (1994) Mutations in the p53 tumor suppressor gene: clues to cancer etiology and molecular pathogenesis. Cancer Res 54:4855

9. Harris CH, Hollstein M (1993) Clinical implications of the p53 tumor-suppressor gene. N Engl J Med 329:1318

10. Kuczyk MA, Serth J, Anton P, Höfner K, Jonas U (1994) Value of p53 immunohistochemistry as an independent prognosticator for superficial bladder cancer. Z Urologic Poster 2/1994

11. Lane DP (1992) P53, guardian of the genome. Nature 358:15

12. Levine AJ (1992) The p53 tumor-suppressor gene. N Engl J Med 326:1350

13. Levine AJ, Momand J, Finlay CA (1991) The p53 tumour suppressor gene. Nature 351:453

14. Marshall CJ (1991) Tumor suppressor genes. Cell 64:313

15. Momand J, Zambetti GP, Olson DC, George D, Levine AJ (1992) The $m d m-2$ oncogene product forms a complex with the $\mathrm{p} 53$ protein and inhibits p53-mediated transactivation. Cell 69:1237

16. Nakopoulou L, Constantinides C, Papandropoulos J, Theodoropoulos G, Tzonou A, Giannopoulos A, Zervas A, Dimopoulos C (1995) Evaluation of overexpression of p53 tumour suppressor protein in superficial and invasive transitional cell bladder cancer: comparison with DNA ploidy. Adult Urol 46:334

17. Sarkis AS, Dalbagni G, Cordon-Cardo C, Zhang Z-F, Sheinfeld J, Fair WR, Herr HW, Reuter VE (1993) Nuclear overexpres- sion of p53 protein in transitional cell bladder carcinoma: a marker for disease progression. J Natl Cancer Inst 85:53

18. Sarkis AS, Dalbagni G, Cordon-Cardo C (1994) Association of p53 nuclear overexpression and tumor progression in carcinoma in situ of the bladder. Br J Urol 73:533

19. Sarkis AS, Bajorin DF, Reuter VE, Herr HW, Netto G, Zhang Z-F, Schultz PR, Cordon-Cardo C, Scher HI (1995) Prognostic value of $\mathrm{p} 53$ nuclear overexpression in patients with invasive bladder cancer treated with neoadjuvant MVAC. J Clin Oncol 13:1384

20. Schmitz-Dräger BJ, Roeyen CRC, Grimm M-O, Gerharz C-D, Decken K, Schulz WA, Bültel H, Makri D, Ebert T, Ackermann $R$ (1994) P53 accumulation in precursor lesions and early stages of bladder cancer. World J Urol 12:79

21. Serth J, Kuczyk MA, Bokemeyer C, Hervatin C, Nafe R, Tan HK, Jonas U (1995) P53 immunohistochemistry as an independent prognostic factor for transitional cell carcinoma of the bladder. Br J Cancer 71:201

22. Tetu B, Fradet $Y$, Allard P, Veilleux C, Roberge N, Bernard P (1996) Prevalence and clinical significance of HER-2/neu, p53 and $R b$ expression in primary superficial bladder cancer. J Urol $155: 1794$

23. Thomas D, Robinson MC, Charlton $R$, Wilkinson $S$, Shenton BK, Neal DE (1993) P53 expression, ploidy and progression in pT1 transitional cell carcinoma of the bladder. Br J Urol 73:533

24. Underwood MA, Reeves J, Smith G, Gardiner DS, Bartlett J, Cooke TG (1996) Overexpression of p53 protein and its significance for recurrent progressive bladder tumours. Br J Urol $77: 659$ 